\title{
Correction to: Microplasma synthesis of silver nanoparticles in PVP solutions using sacrificial silver anodes
}

\author{
O. I. Kuntyi ${ }^{1}$ - A. R. Kytsya ${ }^{2}$ - A. B. Bondarenko ${ }^{1}$ - A. S. Mazur ${ }^{1}$ - I. P. Mertsalo ${ }^{1}$ - L. I. Bazylyak ${ }^{2}$ \\ Published online: 7 July 2021 \\ ○) Springer-Verlag GmbH Germany, part of Springer Nature 2021
}

Correction to: Colloid and Polymer Science (2021) 299:855-863 https://doi.org/10.1007/s00396-021-04811-y

The original version of this paper was published with error in the supplementary information file. Unfortunately, journal production created the supplementary file (ESM 1) using the original manuscript document. Given in this article is the correct supplementary file.

Supplementary Information The online version contains supplementary material available at https://doi.org/10.1007/s00396-021-04859-w.

The original article can be found online at https://doi.org/10.1007/ s00396-021-04811-y.

A. R. Kytsya

kytsya@nas.gov.ua; andriy_kytsya@yahoo.com

1 Department of Chemistry and Technology of Inorganic Substances, Lviv Polytechnic National University, Bandery Str. 12, Lviv 79013, Ukraine

2 Department of Physical Chemistry of Fossil Fuels of the Institute of Physical-Organic Chemistry and Coal Chemistry Named After L. M. Lytvynenko of the National Academy of Sciences of Ukraine, Naukova Str. 3a, Lviv 79060, Ukraine 